\title{
The Rationale for the Choice of Material and Hardening Technology for the Part Transmission Selector Fork of a Truck
}

\author{
${ }^{1}$ Ilnar Rinatovich Mukhametzyanov, ${ }^{2}$ Vladimir Ivanovich Astashchenko, ${ }^{3}$ Gulnara Fagimovna \\ Mukhametzyanova, ${ }^{4}$ Lenar Nurgaleevich Shafigullin \\ 1,2,3,4 Department of Materials, Technologies and Quality at NChI, KFU. \\ ilnarr116m@gmail.com \\ astvi-52@mail.ru \\ gulnara-ineka@mail.ru \\ misharin_82@mail.ru
}

Received: 21st August 2020, Accepted: 14th September 2020, Published: 31st October 2020

\begin{abstract}
They presented the studies of high-quality carbon structural steel chemical composition, microstructure and properties used for the "Transfer case transfer fork turning on" part of a truck, subjected to various methods of surface hardening treatment. Chemical-thermal treatment is used as a hardening treatment for the parts made of high-quality carbon structural steel 20: nitrocarburizing followed by heat treatment, for the parts made of high-quality carbon structural steel 45 - surface hardening with heating by high-frequency currents (HFC) and subsequent self-tempering. They substantiated the choice of material and the technology of hardening processing for the part "Transfer case transfer fork turning on" of a truck. They presented the results concerning the studies of the chemical composition, microstructure and hardness of parts made of steel 20 and steel 45, subjected to various methods of surface hardening treatment. After the study, it was found that the manufacture of the "Transfer case transfer fork turning on" part of a truck requires the use of high-quality carbon structural steel 45 with surface hardening of the part after heating by high-frequency currents and subsequent self-tempering. This significantly reduces the cost of the manufacturing process of the part and improves the quality of hardened parts.
\end{abstract}

\section{Keywords}

Steel; Nitrocarburizing; Surface Hardening; Microstructure; Hardness

\section{Introduction}

"The transfer case transfer fork turning on" part of a commercial vehicle must have high static strength, fatigue resistance and wear resistance. The choice of material for the manufacture of machine-building parts significantly affects the improvement of the quality and reliability of machines, devices and mechanisms, their material consumption, energy consumption and cost; in some cases, the availability of materials depends on the possibility of technical solution implementation. A variety of materials are used in the manufacture and repair of cars, but the main ones are metals, and above all steel. The performance and durability of machines and mechanisms largely depends on the bearing capacity of the mating working surfaces of the parts. The tightening of requirements for geometric accuracy, as well as the use of new high-strength materials for parts, is accompanied by the product cost increase. Therefore, the most effective way to improve the performance properties of products are surface hardening methods. The choice of the most effective hardening technology is based on determination of the properties that affect the life of the part in operation, evaluation of its loading range and determination of the surface layer parameter quality that affects the part performance. To increase fatigue and wear resistance, steel parts experiencing maximum stresses on the surface (bending, contact stresses) are subjected to surface hardening: carburizing, nitrocarburizing, nitriding, boriding and other hardening methods [1-11].

Most car parts are carburized and nitrocarburized. The surface hardness of steel products after carburizing reaches $900 \mathrm{HV}$, and after nitrocarburizing $\sim 1000 \mathrm{HV}$ due to the formation of complex carbonitrides. The experience of using these methods of hardening shows that preference is given to carburizing when it is necessary to impart a large depth of the hardened layer. The thickness of the hardened layer: $0.4-1.8 \mathrm{~mm}$ for cementation; $0.2-0.8 \mathrm{~mm}$ for nitrocarburizing. This is due to the fact that when steel is nitrocarburized to the depth of more than $0.8 \mathrm{~mm}$, defects appear in the hardened layer in the form of internal oxidation and a "dark" component, which sharply reduce the hardness, endurance limit and contact strength. It should be noted that for small parts with a nitrocarburized layer depth less than $0.8 \mathrm{~mm}$, this method has an advantage over carburizing. The parts operating under intense friction wear, under the conditions of alternating loads, but without the influence of a corrosive factor, are subjected to 
cementation - piston pins, camshaft cams, plunger pairs of pumps, pushers, etc. Nitrocarburizing is used to strengthen shafts, axles, gear wheels, bushings, bolts, and nuts [3 -5].

Among the variety of hardening methods, the technologies of surface hardening of parts with heating by highfrequency currents are distinguished by the greatest efficiency and ease of implementation in production conditions. This high-performance, progressive method of heat treatment provides the increase of steel mechanical properties, including the yield point, fatigue and hardness, eliminates the possibility of decarburization, reduces the risk of product surface oxidation and their deformation, creates the prerequisites for comprehensive mechanization and automation of the hardening process. With a hardening depth of up to $5 \mathrm{~mm}$, the surface microhardness of about $750 \mathrm{HV}$ and more can be achieved. It is advisable to use this method of hardening in large-scale and mass production and for the parts when its individual sections are hardened $[4,11]$.

In this work, research was carried out on the metal of the part "Transfer case transfer fork turning on" of the KAMAZ truck made of high-quality carbon steels: steel 20 and steel 45, subjected to various methods of surface hardening treatment.

The purpose of the work is to substantiate the choice of hardening processing material and technology for the "Transfer case transfer fork turning on" part of a truck.

\section{Methods}

The studies of the chemical composition of the part metal were carried out in accordance with GOST 22536.1 - 88, GOST 22536.2 - 87 and GOST 18895 - 97 using the MFS - 8 photovoltaic system, designed for excitation, registration and automatic processing of signals from analytical spectral lines of various elements and an express analyzer AUS 8144 designed for the simultaneous determination of carbon and sulfur in steels, cast iron, and non-ferrous alloys [12 - 14]. The study of the part microstructure was carried out on transverse microsections relative to the axis of the legs using an OLYMPUS BX-51M optical microscope. Hardness measurements were carried out on the surface of the part legs made of steel 20 and 45, according to GOST 9013 - 59 at the load of $150 \mathrm{kgf}$ using a TK-2M device [15].

As a hardening treatment for the parts made of high-quality carbon structural steel 20, they use chemical-thermal treatment (nitrocarburizing followed by heat treatment). The microstructure of steel 20 before chemical heat treatment consists of pearlite and ferrite. Chemical heat treatment of steel is carried out according to the scheme shown on Figure 1.

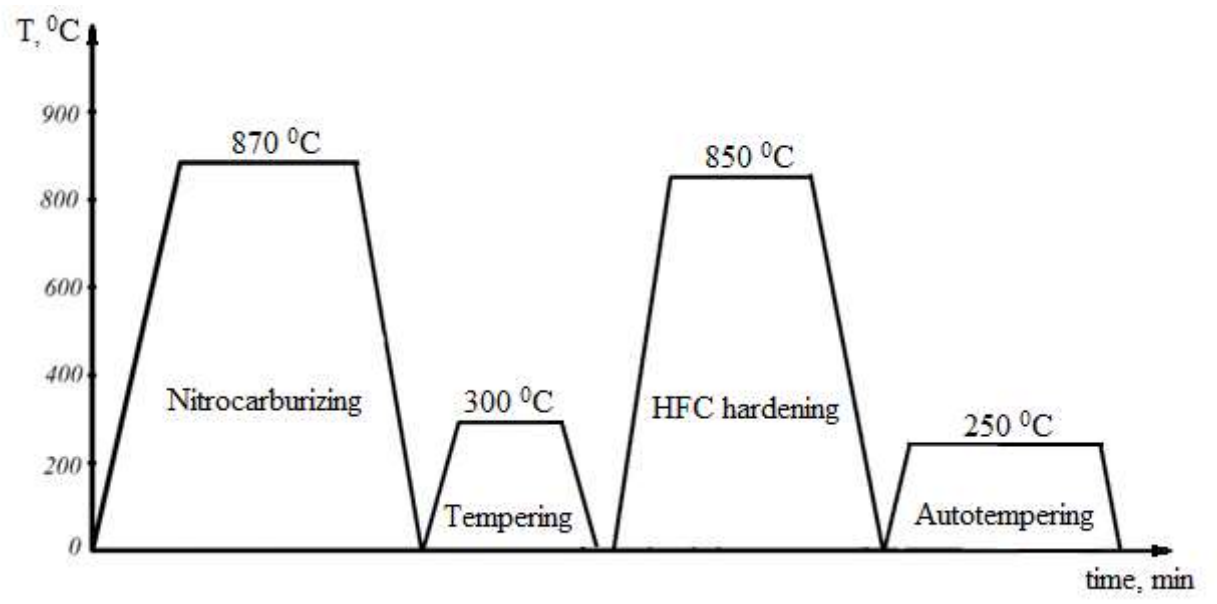

Fig. 1: The Scheme of Chemical-Thermal Treatment of the "The Transfer Case Transfer Fork Turning On" Part Made of Steel 20.

To achieve the required mechanical properties, it is sufficient to use heat treatment with surface hardening with heating by high-frequency currents (HFC) as a hardening treatment for steel 45 , which significantly reduces the cost of the technological process for manufacturing a part and improves the quality of hardened parts. For the manufacture of an experimental batch of the part "The transfer case transfer fork turning on" made of steel 45 , the workpieces were subjected to machining with subsequent hardening treatment (hardening by high-frequency currents + self-tempering). Heat treatment of steel 45 was carried out according to the scheme shown on Figure 2. 


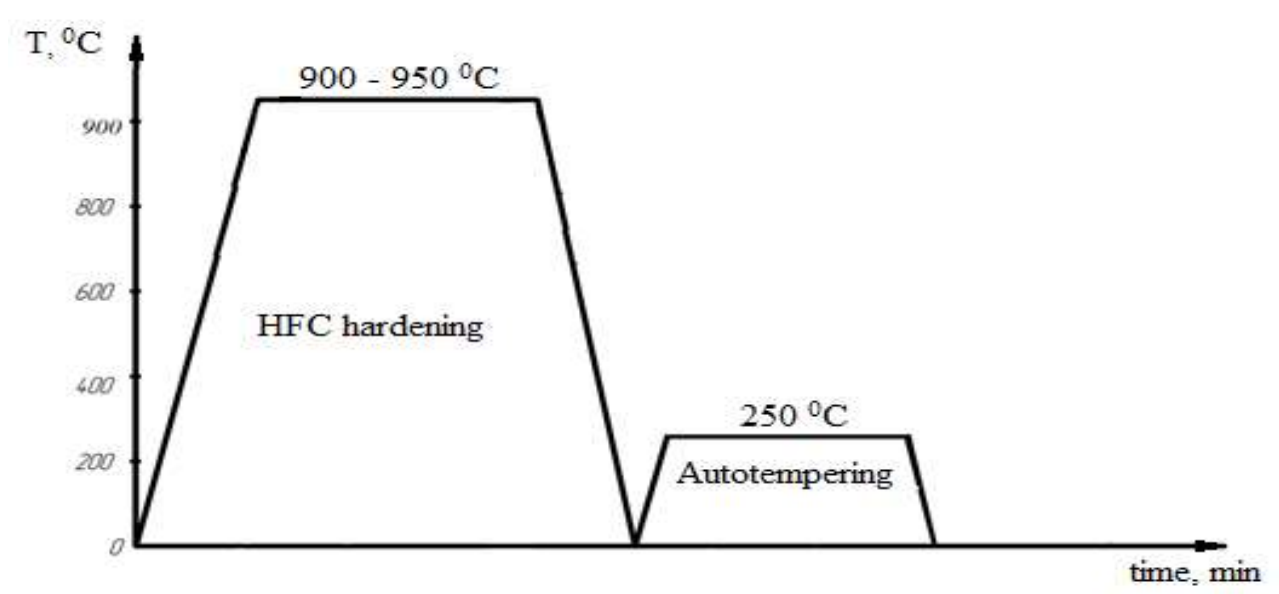

\section{Fig. 2: The Scheme of Heat Treatment of the "The Transfer Case Transfer Fork Turning On" Part Made of Steel 45.}

After the hardening treatment, the samples of the parts were tested for chemical composition, microstructure and hardness, according to the requirements for this type of car parts [4].

The requirements for the "The transfer case transfer fork turning on" part:

- steel 20, GOST 1050-2013. The hardness of HFC surface should be from 59 - 65 HRC, the thickness of the nitrocarburized layer - from 0.3 to $0.5 \mathrm{~mm}$.

- steel 45, GOST 1050-2013. The hardness of the hardened HFC surface should be (56 - 63) HRC. The thickness of the surface hardened by HFC is $2-4 \mathrm{~mm}$.

The samples from steel 20 after nitrocarburizing with subsequent hardening with HFC on the legs and the samples from steel 45 after hardening with HFC were subjected to the study: the specimens from steel 20 after heat treatment, nitrocarburizing followed by hardening with HFC (the sample 1); the samples from steel 45 after hardening with high frequency current (the samples 2, 3,4). Correct selection of heating and cooling temperatures, of heating and cooling rates is very important for the HFC hardening process. Mode 1 (Sample No. 2): $\mathrm{T}_{\text {heating }}$ is $840{ }^{\circ} \mathrm{C}$, heating time - $4 \mathrm{sec}$; $\mathrm{T}_{\text {tempering }}-250{ }^{\circ} \mathrm{C}$, cooling time -5 sec. Mode 2 (Sample No. 3): $\mathrm{T}_{\text {heating }}-900{ }^{\circ} \mathrm{C}$, heating time -9 sec; $\mathrm{T}_{\text {tempering }}-250$ ${ }^{0} \mathrm{C}$, cooling time $-5 \mathrm{sec}$. Mode 3 (Sample No. 4): $\mathrm{T}_{\text {heating }}-950{ }^{0} \mathrm{C}$, heating time $-13 \mathrm{sec}$; $\mathrm{T}_{\text {tempering }}-250{ }^{0} \mathrm{C}$, cooling time - $10 \mathrm{sec}$.

\section{Results and Discussion}

An expensive chemical-thermal treatment (nitrocarburizing with subsequent heat treatment) is used as a hardening treatment for high-quality carbon structural steel 20. To achieve the required mechanical properties, it is sufficient to use heat treatment with surface hardening with HFC heating as a hardening treatment for steel 45, which significantly reduces the cost of the technological process of a part production. The results of the chemical analysis of the part material after various processing methods are presented in Table 1 and Figure 3.

Table 1: The Results of the Chemical Analysis of the Material for the "The Transfer Case Transfer Fork Turning On" Part after Various Processing Methods

\begin{tabular}{|c|c|c|c|c|c|c|}
\hline \multirow{2}{*}{$\begin{array}{c}\text { Specimens } \\
\text { № }\end{array}$} & \multicolumn{6}{|c|}{ The content of chemical elements, wt. \% } \\
\cline { 2 - 7 } & $\mathrm{C}$ & $\mathrm{S}$ & $\mathrm{Si}$ & $\mathrm{Mn}$ & $\mathrm{Cr}$ & $\mathrm{Ni}$ \\
\hline 1 (Steel 20) & 0,21 & 0,010 & 0,22 & 0,40 & 0,07 & 0,09 \\
\hline 2 (Steel 45) & 0,43 & 0,007 & 0,29 & 0,56 & 0,12 & 0,15 \\
\hline 3 (Steel 45) & 0,42 & 0,008 & 0,27 & 0,56 & 0,12 & 0,13 \\
\hline 4 (Steel 45) & 0,43 & 0,008 & 0,28 & 0,57 & 0,12 & 0,14 \\
\hline
\end{tabular}




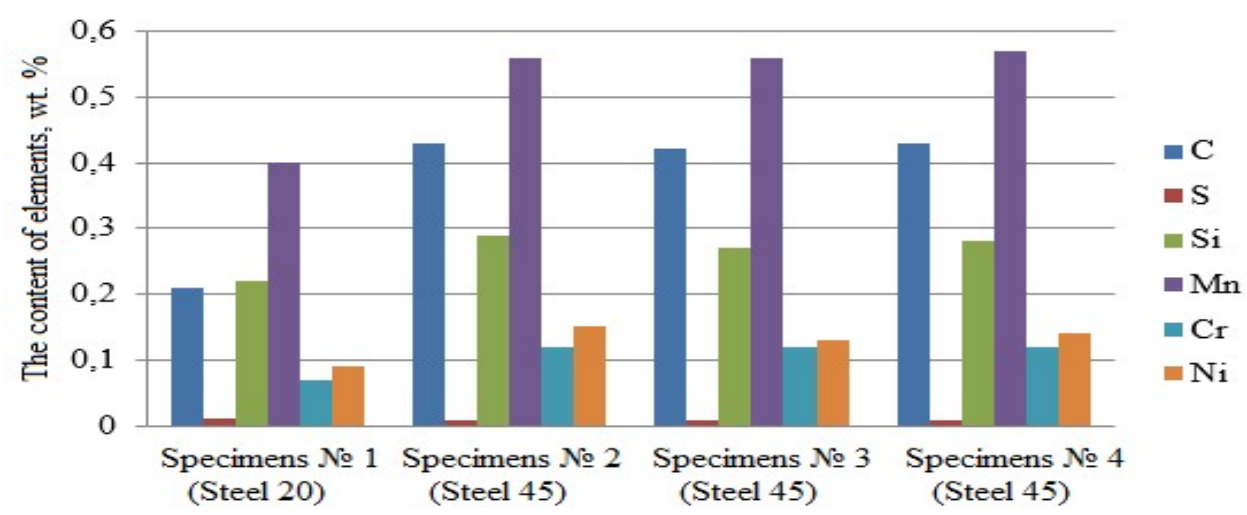

Fig. 3: Results of Chemical Analysis of the Part Material Subjected to Various Methods of Strengthening. After the study, it was found that the chemical composition of the metal for the parts "The transfer case transfer fork turning on" corresponds to steel 20 and steel 45, respectively, specified in GOST 1050 - 2013 [16].

The microstructure of an etched section in a $4 \%$ solution of nitric acid in ethyl alcohol, a nitrocarburized layer of a part made of steel 20 (sample 1) with subsequent hardening with high frequency current on the legs: fine-needle martensite, 3 points according to the GOST 8233 - 56 [17]. The thickness of the cemented layer of the legs is $0.4 \mathrm{~mm}$ (Fig. 4).

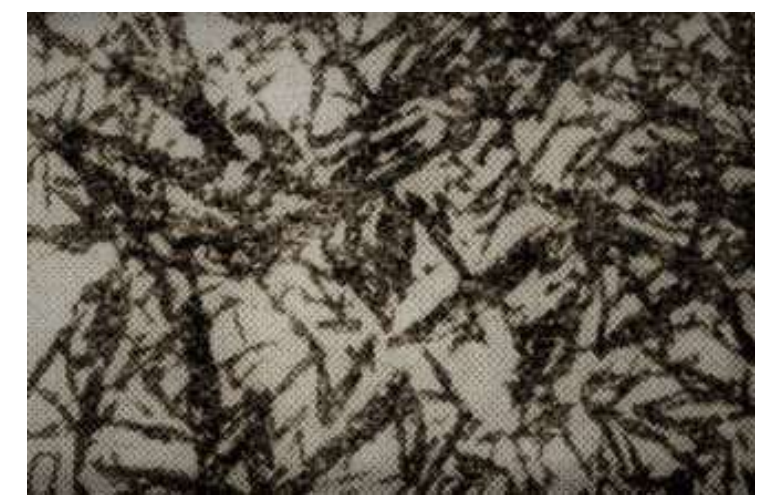

Fig. 4: The Microstructure of the Nitrocarburized Layer followed by HFC Hardening on the Legs of a Part Made of Steel 20 (sample 1), $x 1000$.

The microstructure of the sample 1 meets the requirements for the "The transfer case transfer fork turning on" part. The microstructure of an etched section in a $4 \%$ solution of nitric acid in ethanol of a hardened HFC layer on the legs of the part made of steel 45 (sample 2): martensite and trostomartensite according to the GOST 8233-56 [17]. The thickness of the legs hardened by HFC is $2.0 \mathrm{~mm}$ (Fig. 5).

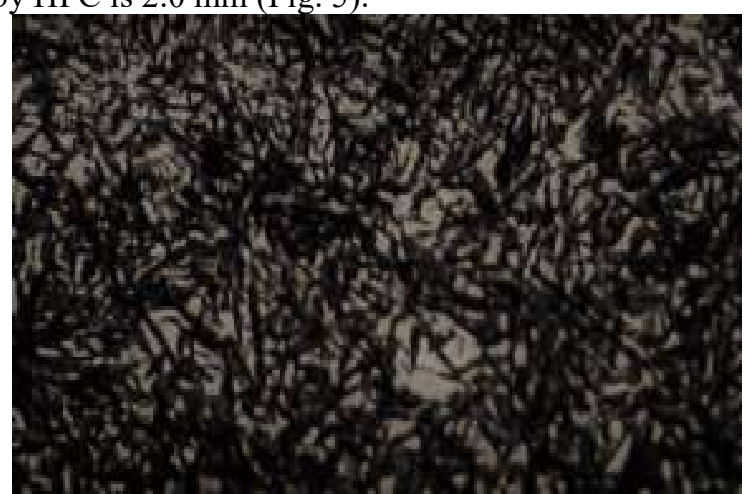

Fig. 5: The Microstructure of the Hardened HFC Layer on the Legs of a Part Made of Steel 45 (sample 2), $x$ 1000.

The microstructure of the sample 2 does not meet the requirements for the "The transfer case transfer fork turning on" part. The reason for the low hardness and inconsistency in the microstructure of the hardened surface was the underestimated heating temperature of the part for steel hardening. 
The microstructure of the etched section in a 4\% solution of nitric acid in ethanol of the hardened HFC layer on the legs of a part made of steel 45 (sample 3): fine-needle martensite, 4 points according to the GOST 8233. The thickness of the hardened HFC layer of the legs is $2.5-2,7 \mathrm{~mm}$ (fig. 6).

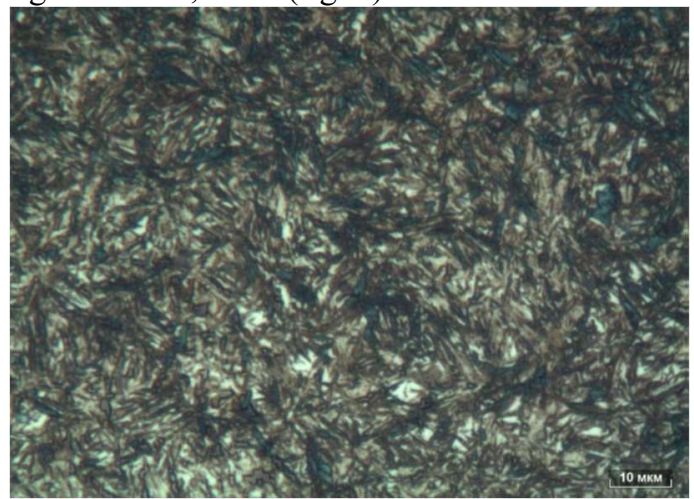

Fig. 6: Microstructure of the Hardened HFC Layer on the Legs of a Part Made of Steel 45 (sample 3), $x 1000$. The microstructure of sample 3 complies with the requirements for the "The transfer case transfer fork turning on" part.

The microstructure of an etched section in a $4 \%$ solution of nitric acid in ethanol of a hardened HFC layer on the legs of a part made of steel 45 (sample 4): medium-needle martensite, 5 points according to the GOST 8233. The thickness of the hardened HFC layer of the legs is $3.0-3,2 \mathrm{~mm}$ (fig. 7).

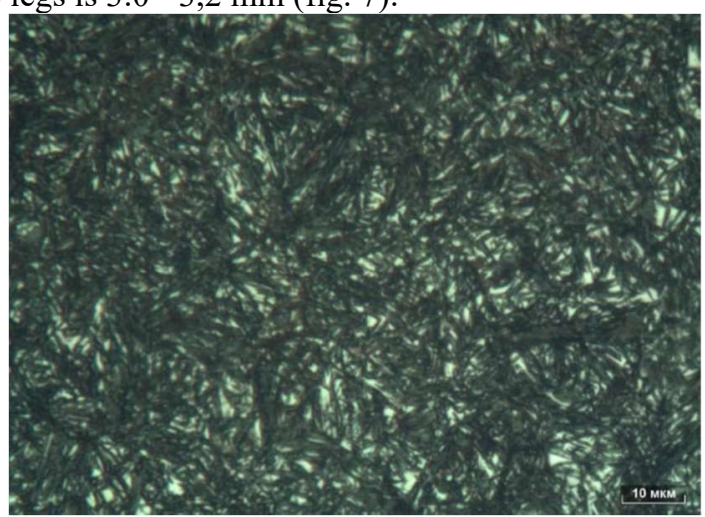

Fig. 7: Microstructure of the Hardened HFC Layer on the Legs of a Part Made of Steel 45 (sample 4), $x 1000$. The microstructure of the sample 4 meets the requirements for the "The transfer case transfer fork turning on" part. The hardness was measured according to the Rockwell method GOST 9013-59 at the load of $150 \mathrm{kgf}$ using a TK-2M device [15]. The results of measuring the part hardness after various methods of hardening are presented in table 2 and on figure 8 .

Table 2: The Results of Measuring the Hardness of the Part "The Transfer Case Transfer Fork Turning On" After Various Methods of Hardening

\begin{tabular}{|c|c|c|c|c|c|}
\hline \multirow{2}{*}{$\begin{array}{c}\text { Specimens } \\
\text { № }\end{array}$} & \multicolumn{4}{|c|}{ Heasurement value, HRC } & \multirow{2}{*}{$\begin{array}{c}\text { Compliance to drawing } \\
\text { requirements }\end{array}$} \\
\cline { 2 - 5 } & 1 & 2 & 3 & Half value & satisfy \\
\hline 1 (Steel 20) & 62 & 64 & 63 & 63 & not satisfy \\
\hline 2 (Steel 45) & 49 & 50 & 49 & 49 & satisfy \\
\hline 3 (Steel 45) & 57 & 59 & 59 & 59 & satisfy \\
\hline 4 (Steel 45) & 60 & 62 & 61 & 61 & \\
\hline
\end{tabular}




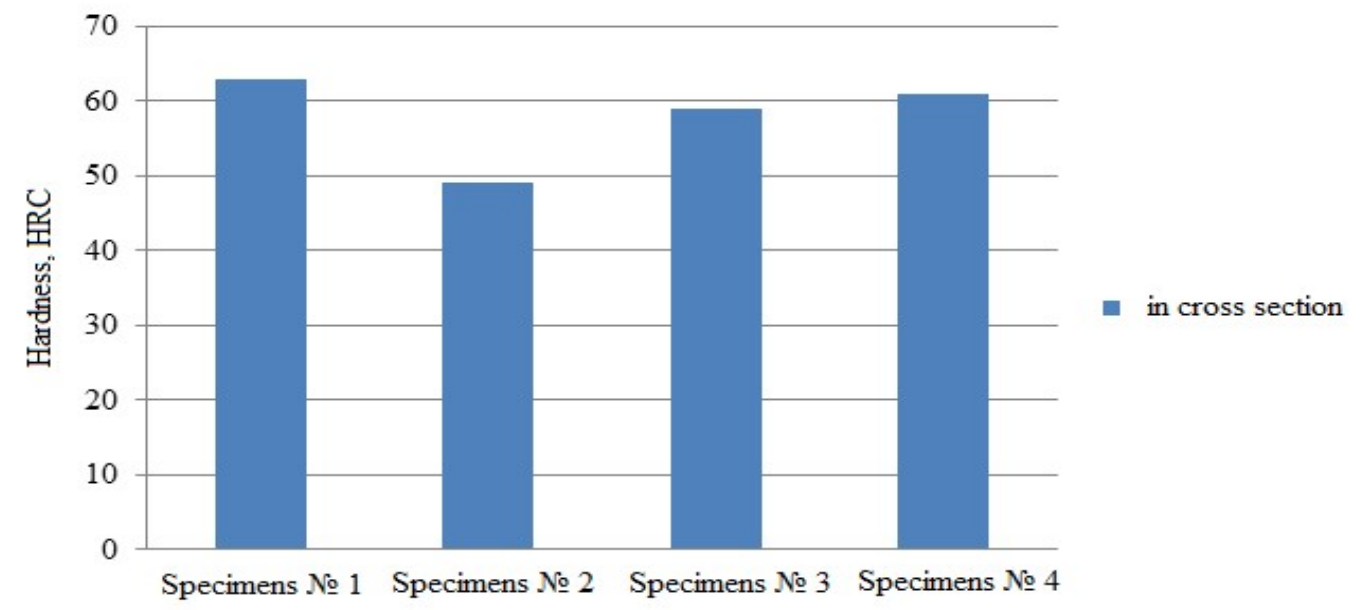

Figure 8: The Results of Measuring the Hardness of the Part after Various Methods of Hardening.

The samples No. 1, No. 3, No. 4 meet the requirements of the drawing for the "Fork turning on" part, namely, the hardness of the nitrocarburized HFC-hardened surface of the sample No. 1 is from $59 \mathrm{HRC}$ to $65 \mathrm{HRC}$, and the hardness of the HFC-hardened surface of the samples No. 3, No. 4 is from 56 HRC up to 63 HRC. The sample No. 2 does not meet the requirements of the drawing, since the surface hardness of the hardened HFC layer is underestimated. After conducting the study to control the quality of HFC hardening (assessment of the microstructure, measurement of the hardness and thickness of the hardened HFC layer) on the samples of materials used for the "Fork turning on" parts of a truck it was found that HFC hardening on samples No. 3, No. 4 was performed in accordance with drawing requirements.

\section{Conclusions}

In the course of the study it was found that it is most expedient to use carbon steel 45 as the material for the "The transfer case transfer fork turning on" part of a truck. The required steel characteristics are achieved as the result of surface hardening with heating by high frequency currents (HFC) and subsequent self-tempering. When surface hardening is carried out, the surface layer of the inclusion plug is heated by HFC to the temperature of $9500 \mathrm{C}$, followed by self-tempering at the temperature of $2500 \mathrm{C}$, which ensures the $2.5-2.7 \mathrm{~mm}$ thickness of the HFC hardened layer and the hardness of the hardened HFC surface of the part layer makes 57-59 HRC.

\section{Summary}

The choice of steels and alloys, as well as the technology of hardening processing of parts, are based on the requirements imposed on them, which are formed in relation to the operating conditions of the product, while taking into account the indicators of its reliability. This is a difficult task. Metallurgy did not develop uniform principles for the choice of metals, since, along with the requirements of the technical plan, it is necessary to take into account the specifics of a part production, saving of metal, and operating conditions of the product. Preference was given to steel 45 with surface hardening of the part after heating with high-frequency currents and subsequent self-tempering for the manufacture of the "The transfer case transfer fork turning on" part of a truck.

\section{Acknowledgements}

The work is performed according to the Russian Government Program of Competitive Growth of Kazan Federal University.

\section{References}

[1] Kartashevich, A.N. (2013). Tractors and automobiles. Construction [Electronic resource]: tutorial- Moscow: Scientific Publishing Center INFRA-M,. - 313 p. - ISBN 978-5-16-006882-4. - Access mode: http://znanium.com/go.php?id=412187.

[2] Zotkin, V.E. (2008). Methodology for choosing materials and strengthening technologies in mechanical engineering: The tutorial. M.: PH "FORUM": INFRA-M, - 320 p.

[3] Lakhtin, Yu.M., \& Leontyev, V.P. (1990). Materials science: The textbook for higher technical educational institutions. M.: Mechanical Engineering, -528 p. 
[4] Calner, V.D. (1984). Quality control of heat treatment for steel semi-finished products and parts: Handbook.M.: "Mechanical engineering",. - 384 p.

[5] Borisenok, G.V., Vasiliev, L.A., Voroshnin, L.G. et al. (1981). Chemical and thermal treatment of metals and alloys. Directory. Ed. by L.S. Lyakhovich. M.: metallurgy,. - 424 p.

[6] Walter, M., Wilzer, J., Mujica Roncery, L., Weber, S., \& Theisen, W. (2014). Carbide precipitation of martensitic tool steels during tempering. European Conference on Heat Treatment and 21st IFHTSE Congress, May, 12th-15th| Munich, Germany, Edited by Hans-Werner Zoch, Reinhold Schneider, Thomas Lübben, ${ }^{0}$ Arbeitsgemeinschaft Wärmbehandlung und Werkstofftechnik e. V. (AWT) Paul-Feller-Str. 128199 Bremen Germany, 2014. - pp. $383-390$.

[7] Astashchenko, V.I., Zapadnova, N.N., \& Mukhametzianova, G.F. (2017). Key concepts for production of highquality parts. IOP Conference Series: Materials Science and Engineering, 240(1), - Art. № 012007.

[8] Kaufmann, B., Autenrieth, H., Hoffmeister, J., \& Schulze, V. (2014). Investigation on Short Time Tempering by Induction Heating of the low alloyed AISI4140 steel. European Conference on Heat Treatment and 21st IFHTSE Congress, May, 12th-15th, | Munich, Germany, Edited by Hans-Werner Zoch, Reinhold Schneider, Thomas Lübben, ${ }^{\circ}$ Arbeitsgemeinschaft Wärmbehandlung und Werkstofftechnik e. V. (AWT) Paul-Feller-Str. 128199 Bremen Germany, 2014. - pp. $373-382$.

[9] Astaschenko, V.I., Zapadnova, E.A., Zapadnova, N.N., \& Mukhametzyanova, G.F. (2016). Predicting structure micro-alloyed steel products for different purposes. IOP Conference Series: Materials Science and Engineering, 134(1), Art. № 012029.

[10] Mukhametzyanova, G.F., Zapadnova, N.N., \& Zapadnova, E.A. (2019). Features of technological materials application in thermal manufacturing. Materials Science Forum, 946, 199-204.

[11] Vildanov, A.G, Mukhametzyanov, I.R, Astaschenko, V.I, \& Mukhametzyanova, G.F. (2019). The investigation of properties of the ball pins of the steering rod of the car. Ad alta-journal of interdisciplinary research, 9(2), 138141.

[12] GOST 22536.1 - 88 (ST SEV 5284-85). (1988). Carbon steel and unalloyed cast iron. Methods for the determination of total carbon and graphite. - M.: Publishing house of standards, - 11p.

[13] GOST 22536.2 - 87 (ST SEV 5283-85). (1987). Carbon steel and unalloyed cast iron. Methods for the determination of sulfur. - M.: Publishing house of standards,. - 13p.

[14] GOST 18895 - 97 Steel. (1997). Photoelectric spectral analysis method. - M.: Publishing house of standards,. $-15 \mathrm{p}$.

[15] GOST 9013 - 59 (ISO 6508-86). (2001). Metals. Rockwell hardness measurement method. - M.: Publishing house of standards, . - 13p.

[16] GOST 1050 - 2013. (2013). Metal products from unalloyed constructional quality and special steels. General technical conditions. - M.: Publishing house of standards, -40 p.

[17] GOST 8233 - 56. Steel. (2004). Microstructure standards. - M.: Publishing house of standards, - 12p. 